\title{
Prognosticators of melanoma, the melanoma report, and the sentinel lymph node
}

\author{
A Neil Crowson¹, Cynthia M Magro² and Martin C Mihm $\mathrm{Jr}^{3}$ \\ ${ }^{1}$ Departments of Dermatology, Pathology and Surgery, University of Oklahoma and Regional Medical \\ Laboratories, St John Medical Center, Tulsa, OK, USA; ${ }^{2}$ Division of Dermatopathology, Department of \\ Pathology, Ohio State University, Columbus, OH, USA and ${ }^{3}$ Departments of Dermatology and Pathology, \\ Harvard Medical School, Massachusetts General Hospital, Boston, MA, USA
}

\begin{abstract}
Since the 1960s, the clinical characteristics of melanoma, its histopathology and its biological basis have been the subject of intense study at pigmented lesion clinics in North America, Europe, and Australia. More recently, the immense database of the Melanoma Committee of the American Joint Committee on Cancer (AJCC) has been exploited through complex mathematical models to measure the impact of various histologic features of primary melanomas and of sentinel lymph node deposits and to correlate these parameters with patient survival. The wealth of modern information available to pathologists and clinicians has become of vital interest to the prognostication of the individual patient with melanoma. The purpose of this review is to bring to the attention of anatomic pathologists the essential characteristics of the pathology report for primary cutaneous melanoma in the modern era.
\end{abstract}

Modern Pathology (2006) 19, S71-S87. doi:10.1038/modpathol.3800517

Keywords: sentinel lymph node; prognostic microstaging; melanoma

Wallace Clark et $a l^{1,2}$ recognized the importance of anatomic compartment of invasion to the prognosis of melanoma. In 1970, Breslow ${ }^{3}$ described the use of an ocular micrometer to specifically measure primary tumor thickness. These two parameters became the recognized prognostic variables available to histopathologists in predicting the biologic behavior of melanoma. ${ }^{4}$ Throughout the 1980s, advances in comprehension of the biology and pathology of melanoma made it apparent that tumors undergo specific growth phases. In particular, neoplasms confined to a histologically defined radial growth phase were proven incapable of generating metastatic events unless regression was seen histologically at the primary site. Subsequent to this, further work carried out through the pigmented lesion clinics of Massachusetts General Hospital and the University of Pennsylvania established that the presence of microscopic satellites within tumors, the presence of brisk mitotic activity, the absence of an inflammatory infiltrate and in

Correspondence: Dr AN Crowson, MD, Regional Medical Laboratories, St John Medical Center, 1923 S Utica Avenue, Tulsa, OK 74104, USA.

E-mail: ncrowson@sjmc.org

Received 19 September 2005; accepted 28 September 2005 some circumstances the presence of vascular invasion could modify the behavior of a neoplasm.

More recently, the American Joint Committee on Cancer (AJCC) Melanoma Committee, representing the expertise of major melanoma centers in the United States, Europe, and Australia and cancer cooperative groups in several countries recommended a major revision of the TNM staging system following the analysis of prognostic and staging data of 17654 prospectively enrolled melanoma patients. ${ }^{5-7}$ In all, thirteen cancer centers and cooperative groups registered data on 30450 patients for whom full staging information was available for the aforementioned 17 654. Most had followup in excess of 10 years. Prognostic variables accounted for included tumor thickness, ulceration, level of invasion, anatomic site, satellites, in transit metastases (defined clinically), gender, age, sentinel lymph node status, elective lymph node status, therapeutic lymph node status, number of positive nodes, and sites of distant metastasis, correlated to dates of relapse and disease-specific survival. The results of a complex multivariate statistical analysis showed through a Cox regression model that thickness was the most powerful predictor of biological behavior, followed by ulceration, age (over 60 years), anatomic site (trunk), Clark level and gender. These factors all had $P$-values ranging from 0.00001 to $0.001 .^{5-7}$ 


\section{Prognostication including microstaging of melanoma}

The prognosis of patients with invasive melanoma in vertical growth phase can be predicted by specific light microscopic parameters including the measured depth, mitotic count, host response, sex, anatomic site, and presence or absence of regression, angioinvasion, or ulceration. All of this information should appear in the pathology report. ${ }^{8}$

\section{Vertical growth phase melanoma}

\section{Introduction and Clinical Features}

The presence of the vertical growth phase signifies the acquisition by a melanoma of the capacity for metastasis. The vertical growth phase usually manifests as a pigmented or amelanotic nodule supervening on a pre-existing macule or plaque, the sole exception being nodular melanoma that results from the rapid appearance of a malignant neoplasm in previously unremarkable skin. Nodular melanoma lacks a radial growth phase by definition. ${ }^{2,8-11}$ The histologic descriptions that follow for vertical growth phase melanoma apply whether one is considering the acquisition of a vertical growth phase arising in a radial growth phase lesion of lentigo maligna melanoma, acral lentiginous melanoma, or superficial spreading melanoma, or to the de novo vertical growth phase of nodular melanoma. Therapy and prognostication depend on the pathologist's ability to accurately identify by light microscopy the vertical growth phase, as it defines the point in lesional evolution when a melanoma acquires the ability to metastasize and to kill the patient. ${ }^{12-15}$

\section{Radial vs Vertical Growth Phase}

The radial growth phase comprises neoplastic melanocytes growing in a horizontal array as single cells and small nests predominantly in an intraepidermal location. The radial growth phase may also involve the papillary dermis (ie Clark level II) (Figure 1). The latter phenomen describes a microinvasive melanoma and is similar to other concepts of early microinvasive cancer of diverse types. The work of Guerry et $a l^{16}$ in Philadelphia showed that radial growth phase neoplasms, in the absence of regression, were biology indolent and lacked a metastatic capacity. Others have emphasized the uniformly excellent survivorship-approaching $100 \%$ - for patients with thin melanomas ( $\leq 1.0 \mathrm{~mm}$ in thickness) when confined to the radial growth phase. ${ }^{9,10}$ An Australian study of 1716 patients with radial growth phase melanoma showed metastases in only $67(3.9 \%)$, all of whom had regression in their primary tumors. ${ }^{17}$ Another series showed acquisition of early vertical growth

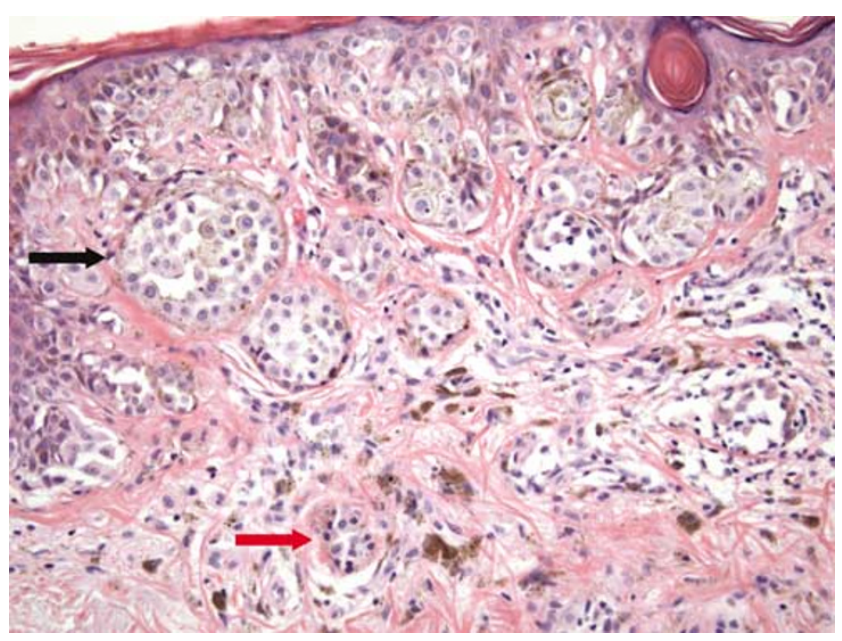

Figure 1 Radial growth phase melanoma: The radial growth phase is incapable biologically of generating metastatic events, save for specific and uncommon circumstances. In this example, there is pagetoid spread of fully transformed malignant epithelioid melanocytes within the epidermis above the basement membrane zone in concert with a level II component in the papillary dermis. Note that the dermal component comprises small nests of neoplastic melanocytes (red arrow) with a similar cytology to those seen above the basement membrane zone which separates them from the overlying epidermal component (black arrow). The dermal nests of radial growth phase melanoma are smaller than those seen in the overlying epidermal component.

phase to be associated with mortality in 12 patients with thin melanomas $<0.76 \mathrm{~mm}$ at Clark level II. ${ }^{18}$ In summation, the radial growth phase melanoma is virtually always curable by complete local excision with rare and specific exceptions. The radial growth phase is usually accompanied by a dermal lymphocytic inflammatory response that has no prognostic significance in this setting.

\section{Early Vertical Growth Phase}

Clark et $a l^{10}$ described the early vertical growth phase and distinguished it from the radial growth phase by criteria that included, most importantly, the presence of a dominant nest within the papillary dermis. This expansile nest is larger than any nest within the epidermis or the surrounding dermis (Figure 2). Clark suggested that the nodule should have 25-50 cells to aid in its identification, and that the cells comprising this nodule are cytologically distinct from those of the intraepidermal component by virtue of their different characteristics, be they of shape, size, nuclear or cytoplasmic features, or the presence or absence of pigment. The presence of regression, especially if extensive (ie, greater than $75 \%$ of tumor volume), may signal an enhanced capacity for metastatic behavior. ${ }^{19,20}$ Incipient vertical growth phase melanoma typically does not fill the papillary dermis and manifests level II or incipient level III invasion. The presence of the early vertical growth phase imputes a risk for 


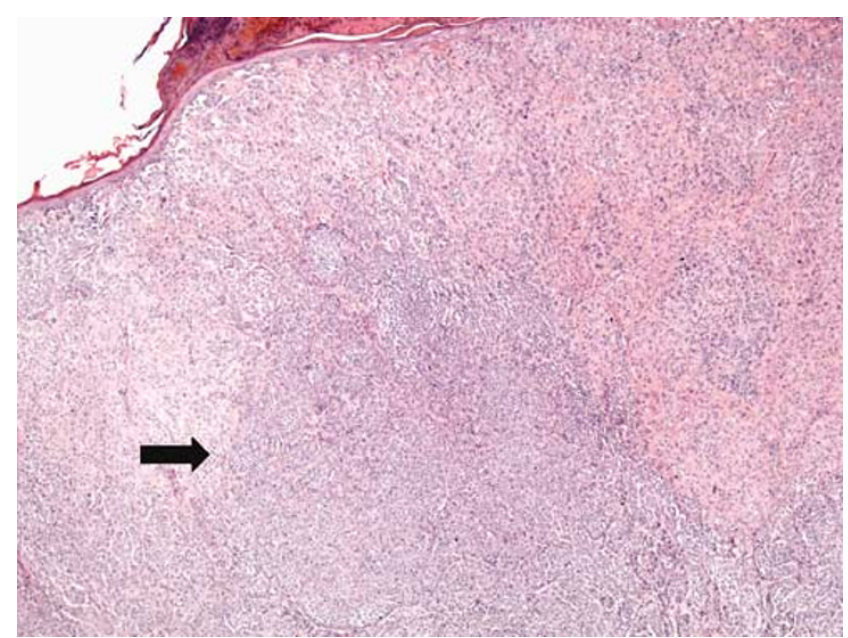

Figure 2 Vertical growth phase melanoma: The vertical growth phase signifies the point at which the melanoma becomes biologically capable of producing metastatic events. Note that there is a dominant expansile dermal nest of neoplastic melanocytes (arrow) which is larger than any of the overlying theques at the dermal-epidermal junction or within the epidermis. Furthermore, the cytology is typically distinctive in the dominant nest. Mitoses are often present. In the fully evolved vertical growth phase these dominant nodules are noted at level III or IV, while the incipient vertical growth phase tumor would be confined to the papillary dermis (ie Clark level II).

metastasis of roughly $10 \%$ at 8 years' follow-up. ${ }^{21} \mathrm{~A}$ recent study showed that a mitotic rate of greater than zero or a thickness greater than $0.76 \mathrm{~mm}$ can be associated with positive sentinel lymph nodes in up to $12 \%$ of patients. ${ }^{22}$ Patients with lesions of similar thickness which were not mitotically active had virtually no metastatic disease. In summation, patients with level II tumors less than $0.76 \mathrm{~mm}$ in thickness with an early vertical growth phase, ulceration of the primary tumor, extensive regression, or mitotic activity are at risk for metastatic disease.

\section{Fully Evolved Vertical Growth Phase Melanoma}

Fully evolved vertical growth phase melanoma is defined by the following criteria: (1) the presence of a dominant nest within the dermis filling and widening the papillary dermis and extending to the papillary-reticular dermal interface or into the reticular dermis and/or subcutaneous fat (Clark levels III, IV, and V) comprising; (2) cells with a distinct cytomorphology different from the intraepidermal radial growth phase component when present, often with; (3) mitoses. This defining, expansile nest is larger than any nest within the epidermis or surrounding dermis, and is classified by cell type in order to avoid the potentially fatal error of overlooking a sometimes subtle phenomenon and also because certain of the subtypes have specific biological characteristics. ${ }^{8}$ An inflammatory response is usually present and is of prognostic significance.

\section{Cell types of the vertical growth phase}

\section{Epithelioid Vertical Growth Phase}

Most often the vertical growth phase comprises epithelioid melanocytes with a round or cuboidal cytoplasmic profile, round or oval nuclei with coarse, spiculated chromatin, prominent nucleoli, and chromatinic rims that are irregular in thickness and contour (Figure 3a). Cytoplasms are often abundant with an eosinophilic staining quality and variable melanization. Cell cohesion is variable. Vertical growth phase nodules typically distort the architecture of the papillary or papillary and reticular dermis. Mitotic figures of both typical and atypical types are often apparent. The latter manifest as tri-, tetra-, or pentapolar mitoses that reflect an aneuploid DNA content or chromosomal lags that signify the presence of double minutes (ie extra pieces of DNA that represent small chromosome-like structures from amplified proto-oncogenes), neardiploid aneuploidy, or aberrancy of the centromere/ spindle apparatus. A variant of epithelioid vertical growth phase is the nevoid melanoma. Some studies have shown a significant tendency for the epithelioid vertical growth phase melanoma to manifest metastases preferentially over other vertical growth phase morphologies. ${ }^{23}$

\section{Spindle Cell Vertical Growth Phase}

The spindle cell vertical growth phase is a form of vertical growth phase usually observed in lentigo maligna melanoma, acral lentiginous melanoma or in other melanomas arising in acral or mucosal sites (ie mucosal lentiginous melanoma). Fascicles of hyperchromatic fusiform cells extend at various angles from the epidermis into the dermis (Figure $3 b)$. One observes no progressive diminution in cell size or in the overall size of the fascicles as one approaches the base of the lesion from above. There is evidence that the spindle cell vertical growth phase has a better prognosis than the epithelioid vertical growth phase. ${ }^{14} \mathrm{~A}$ variant of spindle cell melanoma, the desmoplastic melanoma, tends to recur locally but uncommonly metastasizes. ${ }^{24-30}$ It has been suggested that those desmoplastic melanomas having foci of conventional vertical growth phase melanoma manifest a significantly worse prognosis, with regional lymph node metastases in $10 \%$ of cases as opposed to only $1 \%$ of patients with pure desmoplastic melanoma. ${ }^{31}$ Disease-specific 5year mortality in one study was $11 \%$ for pure desmoplastic vertical growth phase tumors, vs $31 \%$ for those neoplasms having the aforementioned hybrid morphology. ${ }^{31}$ The tendency for desmoplastic melanoma to manifest neurotropism and striking stromal collagenization can be explained at the molecular level by gene expression profiling that shows activation of genes encoding for neurotrophic factors and for extracellular matrix elaboration, ${ }^{30}$ 

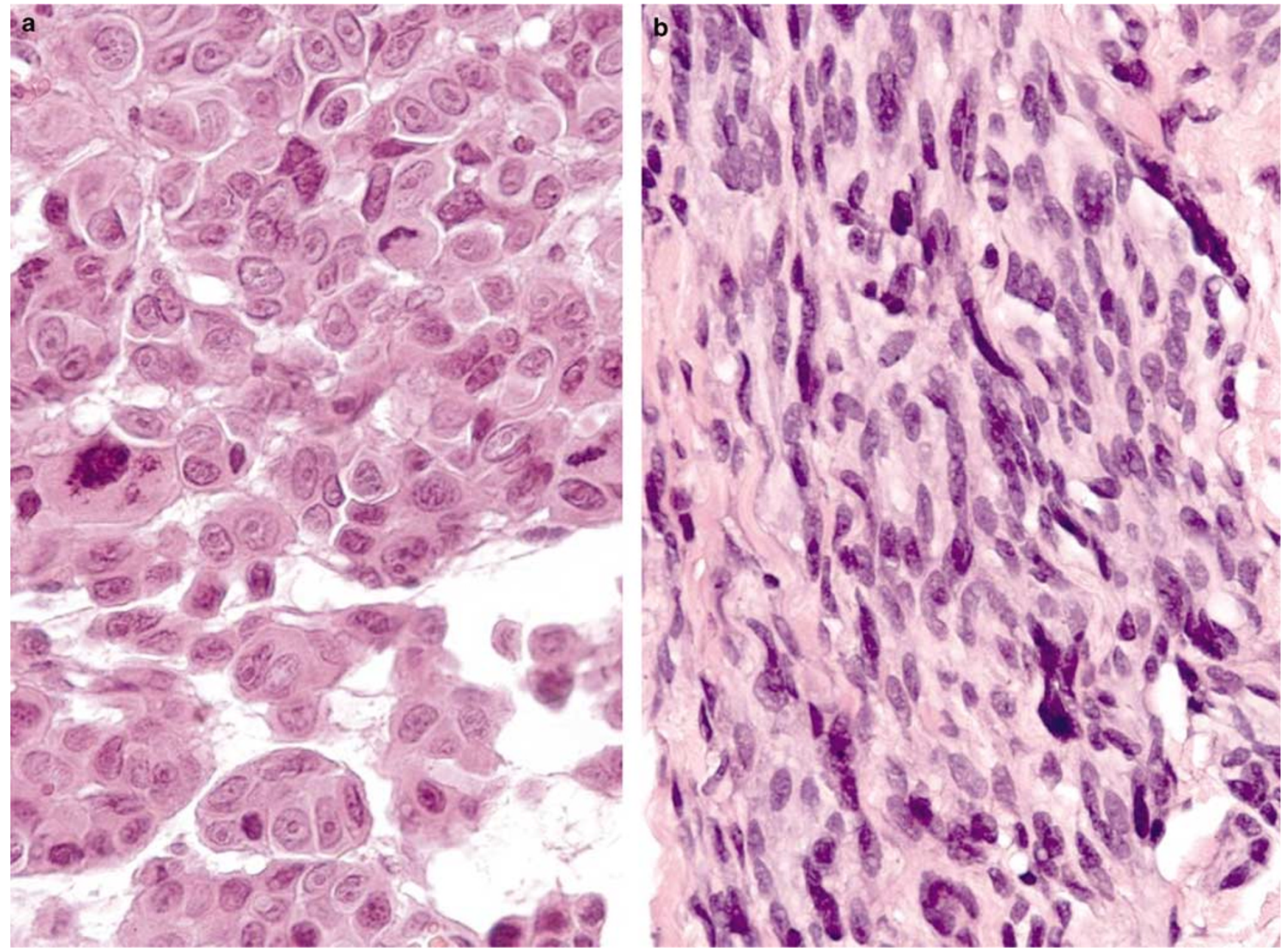

Figure 3 Vertical growth phase phenotypes, classic: The left hand panel (a) demonstrates classic epithelioid vertical growth phase melanoma. This is the form of vertical growth phase most commonly associated with widespread metastases. The right-hand panel (b) shows a spindle cell vertical growth phase with wavy or fusiform, hyperchromatic nuclei, mimicking those of Schwann cell derivation. This form of vertical growth phase is prone to stubborn local recurrence and neurotropism, but less frequently causes widespread metastatic disease.

demonstrated at the protein level in fixed tissues by immunohistochemical assay for p75 nerve growth factor receptor ${ }^{32}$ and basic fibroblast growth factor. ${ }^{33}$ The expression of genes for melanocytic differentiation is reduced in desmoplastic melanoma as compared to conventional melanoma. This reduced expression of melanocyte differentiation genes has as its counterpart at the tissue level absent expression of melanocyte lineage-specific markers such as HMB-45 and Melan-A. ${ }^{28}$ There is little doubt that desmoplastic melanoma manifests up to a three-fold greater thickness at presentation but nonetheless has better survivorship than conventional melanomas of similar thickness. ${ }^{31}$

\section{Histologic type of melanoma}

Since the 1970s melanomas have been histologically subclassified as belonging to four major groups: superficial spreading, lentigo maligna, acral lentiginous, and nodular melanoma. ${ }^{2,34,35}$ The significance of these different melanoma subtypes remains a controversial subject. Some observers suggest that the relatively greater survivorship seen in lentigo maligna melanoma vs the other histologic subtypes is reflective of lesser thickness at time of diagnosis. ${ }^{10,36,37}$ It is apparent that the thickness of primary melanoma at time of initial diagnosis shows progressive diminution in nodular $v s$ superficial spreading vs lentigo maligna melanoma. ${ }^{38}$ However, our contention is that this reflects reproducible differences in the biology of each process, thus, nodular melanoma, which manifests a vertical growth phase de novo would naturally be expected to have the greatest thickness and also to contain, by definition, a clone or clones of neoplastic cells capable of metastatic progression. In contrast, lentigo maligna melanoma, arising in a lentigo maligna manifesting as a persistent pigmented 
macule or plaque years prior to invasion, ${ }^{39}$ would be obvious clinically and so potentially treatable at an early and curable stage. The lifetime risk for developing invasive disease in a lesion of lentigo maligna has been estimated to be only in the $5 \%$ range. ${ }^{39}$ The worse prognosis of acral lentiginous melanoma ${ }^{40}$ has been attributed not to its histomorphology, but to its location in acral glabrous skin. ${ }^{41,42}$ The thinner dermis in acral sites lends itself to greater Clark levels of invasion despite lesser Breslow thickness, and so to access to largercaliber blood vessels early in evolution. The early work of Fidler ${ }^{43}$ suggests that those are the blood vessels capable of accommodating the large tumor bolus conducive to the establishment of the metastatic seed and so suggest that this is a critical factor in the lethality of any given acral melanoma. Although the significance of histologic type may be diminished in multivariate analysis, ${ }^{44}$ it seems to us that common sense trumps statistics when assiduously applied.

\section{Level and Depth of Invasion}

A critical factor is the extent of invasion into the dermis. $^{45}$ Tumor invasion may be qualitatively expressed according to the anatomic compartment of invasion (ie, the papillary or reticular dermis or subcutis), which is referred to as the Clark level, or quantitatively assessed as the Breslow measurement, the thickness of the melanoma from the most superficial aspect of the granular cell layer to the deepest point of invasion into the dermis. Adventitial dermal invasion is not measured unless it is the only site of dermal invasion, and one then measures from the inner luminal surface of the eccrine gland or duct or the inner aspect of the outer root sheath epithelium of the hair follicle. ${ }^{3}$

\section{Thickness (Breslow)}

In the accumulated experience of numerous investigators over a long period of time, tumor thickness as measured by ocular micrometer has emerged as the most powerful predictor of outcome in primary cutaneous melanoma. ${ }^{3,6,10,11,46-54}$ The Breslow measurement is taken from the epidermal surface or, in the event that the surface is ulcerated, from the base of the ulcer, and is made with a calibrated ocular micrometer. ${ }^{3}$ Long clinical follow-up indicates that melanoma thickness is a continuous variable associated with dropout of survivors beyond 10 years. Thus, whereas formerly a tumor of $0.76 \mathrm{~mm}$ thickness was held to have a 99\% survival rate at 5 years (and thus a virtual statistical certainty of 'cure'), a large cohort of patients with tumors of that thickness, when followed out to 10 years, shows only a 90-92\% survivorship. Patients with tumors $1.0 \mathrm{~mm}$ in thickness have a $20 \%$ likelihood of mortality at 10 years for reasons discussed above, while those with tumors over $4.0 \mathrm{~mm}$ in thickness have roughly a $50 \%$ mortality at 10 years. The Breslow measurement is the most important means of prognosticating mucosal melanomas that lack the anatomic compartmentalization seen in the skin. ${ }^{20}$ In most prognostic studies, the measured depth emerges as the most powerful independent factor for prediction of lymph node metastasis and survival. ${ }^{55}$

\section{Anatomic compartment of invasion (the 'Clark level')}

Clark's levels are defined as follows: ${ }^{2}$

Level I: Malignant melanocytes are confined to the epidermis

Level II: Partial infiltration of the papillary dermis by single cells or small nests of cells

Level III: Tumor cells fill and expand the papillary dermis with extension of tumor to the papillaryreticular dermal interface, the latter identifiable through the routine use of a polarizer and compensator to take advantage of the birefringence patterns of the dermal collagen; the papillary dermal collagen fibers are oriented vertically whereas the reticular dermal collagen bundles have a more horizontal orientation. In level III invasion, a few cells may infiltrate the superficial reticular dermis, but the growth is not permeative. Level III penetration usually signifies vertical growth phase melanoma. ${ }^{8,56}$

Level IV: Melanoma cells infiltrate the reticular dermis in a significant fashion.

Level V: Melanoma cells infiltrate the subcutaneous fat.

Although the measured thickness emerges as a more powerful prognosticator than the anatomic compartment of invasion in most series, for thin melanomas $\leq 1.0 \mathrm{~mm}$ in depth, the Clark level remains a powerful independent prognostic variable, second only in importance to ulceration. ${ }^{6}$ One German database showed that a Clark level III tumor had a 3.5 times greater risk of disease progression than did a level II tumor in melanomas $\leq 1.0 \mathrm{~mm}$ in thickness. ${ }^{57}$

\section{Mitotic Rate}

Several large studies have emphasized the prognostic importance of the mitotic rate. The mitotic rate should be reported in any melanoma showing a vertical growth phase component, and is expressed as a mitotic index, namely, the number of mitoses in a square millimeter. From 3 to 10 high-power fields is equivalent to $1 \mathrm{~mm}^{2}$, depending upon the nature of optical equipment used. There is wide variance between different microscope makes and models and we recommend calibration using a stage micrometer. ${ }^{8,56}$ In Clark's original work on mitotic activity, 0 vs $1-6$ vs $>6$ mitoses per square millimeter were the break-points of analysis. ${ }^{58}$ It is important to 
recognize that mitotic 'hot spots' occur in tumors and that sampling can therefore be an issue. Clark advised studying sections for a few minutes to identify the areas of highest mitotic activity and beginning the formal count at that location. Mitotic rate links to tumor thickness in multivariate analy$\operatorname{sis}^{37}$ but remains an independent variable in several studies. ${ }^{10}$ Some authors have advocated the use of a 'prognostic index' defined by a combination of mitotic rate and tumor thickness. ${ }^{59,60}$

In 3661 patients from Australia, the mitotic rate was the most statistically powerful prognosticator of survival after thickness. ${ }^{61}$ A mitotic rate of 1 or more per square millimeter was associated with a significant reduction in survivorship, ${ }^{61}$ although in this data step-wise increases in mitotic activity did not show significant proportionate reduction in survival. ${ }^{62}$ The Philadelphia group has shown a 10 -year metastatic rate in men with vertical growth phase melanoma of $31 \%$ when a mitotic rate of greater than 0 was identified, vs a $4 \%$ mortality rate when the mitotic rate was $0 .^{63}$ Barnhill et al ${ }^{58}$ studied the impact of mitotic rate upon survival for 650 consecutive primary cutaneous melanoma patients in a logistic regression model. Using 0 vs $1-6$ vs $>6$ mitoses per square millimeter as their discriminative categories, they found that both moderate (1-6/ $\left.\mathrm{mm}^{2}\right)$ and high $\left(>6 / \mathrm{mm}^{2}\right)$ mitotic activity were independent prognostic variables. ${ }^{58}$ In particular, the highest mitotic index category was associated with an 11.6-fold increase in relative mortality at 5 years follow-up. ${ }^{58}$

A surrogate marker for mitotic activity can be found in those nuclear factors that serve as indicators of proliferative activity, several of which have been used in an attempt to distinguish benign from malignant melanocytic proliferations. MIB-1 is a monoclonal antibody that recognizes a Ki-67 epitope, but, unlike Ki-67 antibody, which until recently required fresh or frozen tissue, MIB-1 antibody has been available for over a decade in formalin-fixed, paraffin-embedded material. ${ }^{64}$ Ramsay and co-workers found a significant reduction in cause-specific survival in thick $(>4.0 \mathrm{~mm}$ Breslow depth) Stage I melanomas with high MIB-1 reactivity (defined as $>20 \%$ of tumor cells decorating). A similar analysis in a small series of thin melanomas showed a statistically insignificant correlation with behavior, perhaps reflecting the small sample size. ${ }^{65}$ The same observers did find a progressive increase in MIB-1 expression from benign nevi through primary melanomas to metastases as well as a significant correlation with Clark level of invasion and Breslow depth. ${ }^{65}$ Proliferating cell nuclear antigen (PCNA) is a polymerase accessory protein expressed during the cell cycle from $G_{1}$ to $G_{2}$, peaking at the $G_{1} / S$ phase. A monoclonal antibody to PCNA that reacts in formalin-fixed, paraffinembedded tissue has been developed. The PCNA index, as defined by the number of positive staining cells per 1000 tumor cells, is different in benign nevi vs melanoma, averaging 7.2 in nevi and 248.5 in malignant melanoma. ${ }^{66}$ In one study, the PCNA index proved more efficacious than the Breslow depth in predicting locoregional recurrences and metastases. ${ }^{67}$ The predictive value of $\mathrm{Ki}-67$ correlated more closely in one study of uveal melanoma with S phase, shorter survival, histological type, and tumor size than did PCNA expression. ${ }^{68}$ Others found both Ki-67 and PCNA markers to correlate with survivorship in a study of 93 consecutive melanomas; ${ }^{69}$ there was correlation of metastatic behavior to PCNA expression in a study of 143 melanomas in which Ki-67 expression was not assessed. ${ }^{70}$ One study of level III and IV melanomas found no correlation of survivorship with PCNA or Ki-67 expression; however, in that study, flow cytometric analysis showing an aneuploid DNA content was associated with a higher risk of metastatic progression. ${ }^{71}$

\section{Tumor-Infiltrating Lymphocytes (TILs): the Inflammatory Host Response}

A lymphocytic response to the vertical growth phase component influences prognosis in some studies. The presence of TILs was shown to be a significant prognostic factor by Clemente et al, ${ }^{72}$ confirming Clark's observation from 1989 concerning the significance of TILs in melanoma prognosis. ${ }^{8,10,56} \mathrm{~A}$ brisk infiltrate was defined as either a diffuse infiltrate of lymphocytes throughout the vertical growth phase or the presence of infiltrating lymphocytes along $90 \%$ of the circumference of the lesional base (Figure 4). The nonbrisk infiltrate comprised only focal infiltration. An absent lymphoid infiltrate was one in which there were no lymphocytes admixed with melanoma cells, even if they were present in a perivascular array within the tumor or in a perivascular disposition beyond the tumor border but not abutting the tumor cells. Survival differences were highly significant, being $77 \%$ at 8 years for patients whose tumors showed brisk infiltration, $53 \%$ for those with nonbrisk infiltration and $37 \%$ for those whose tumors were designated as having absent TILs. ${ }^{72}$ Not surprisingly, the assessment of the intensity and distribution of the host lymphocytic infiltrate has a significant subjective component. This impacts the reproducibility of this criterion and lowers its predictive power in the hands of some authors. ${ }^{73}$ Image analysis has been employed to reduce the impact of subjectivity and in one study was found to generate statistically significant prognostic data. ${ }^{74}$ The presence of plasma cells ${ }^{75}$ and macrophages ${ }^{76}$ has been suggested to impact prognosis as well.

\section{Regression}

Complete regression, characterized by an area of absent melanocytic growth in the epidermis and 


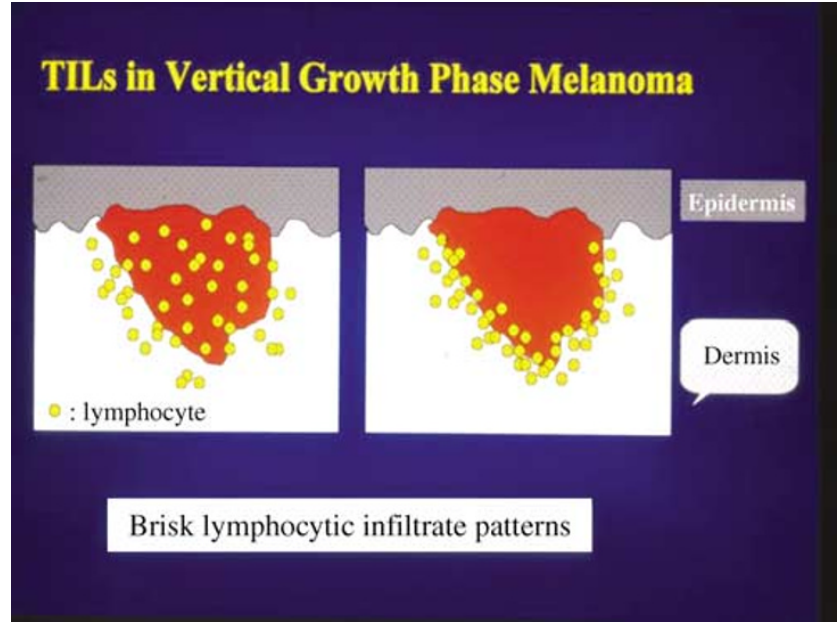

Figure 4 Tumor-infiltrating lymphocytes: Depicted are the two patterns of tumor-infiltrating lymphocytes which would be designated as 'brisk' and which would be a positive prognostic sign. In the left panel, lymphocytes diffusely infiltrate the melanoma mass and break up neoplastic melanocytes into groups and single cells. In the right half of the panel, tumor-infiltrating lymphocytes surround $90 \%$ of the peripheral margin of the melanoma nodule. Either of these two patterns constitutes a 'brisk' lymphocytic infiltrate.

dermis, often bordered on one or both sides by melanoma, may signify a worse prognosis. ${ }^{19,41,77-80}$ The epidermis is often attenuated with loss of the retiform pattern. The subjacent dermis shows a nonlaminated fibroplasia containing a few inflammatory cells and melanophages with variable edema and telangiectasia, the vessels typically assuming a perpendicular orientation to the long axis of the epidermis (Figure 5). Not all investigators have found regression to have a significant survival impact. ${ }^{72,81-83}$ In the study of Barnhill et al, regression, when not assessed quantitatively or semiquantitatively, did not emerge as a significant variable. ${ }^{58}$ Regression of over $75 \%$ of a given tumor may be the critical volume that portends metastasis. ${ }^{19,84}$ One case-control study confirmed that extensive regression was present in $42 \%$ of melanomas $<1 \mathrm{~mm}$ in thickness that metastasized, vs only $5 \%$ of thin melanomas that did not. ${ }^{85}$

\section{Microscopic Satellites}

Microscopic satellites, characterized by reticular dermal and/or subcuticular nodules of tumor greater than $0.05 \mathrm{~mm}$ in width separated from the main vertical growth phase component (Figure 6), are associated with lymph node metastasis, and with decreased disease-free and overall survival. ${ }^{10,53,86-89}$ Clark et $a l^{10}$ found a reduction of actuarial 8-year survival from 75 to $40 \%$ when satellites were identified. It has been suggested that this is a difficult criterion to assess, as tumor tongues radiating from the main vertical growth phase nodule may mimic satellites due to artifacts of sectioning. ${ }^{73}$

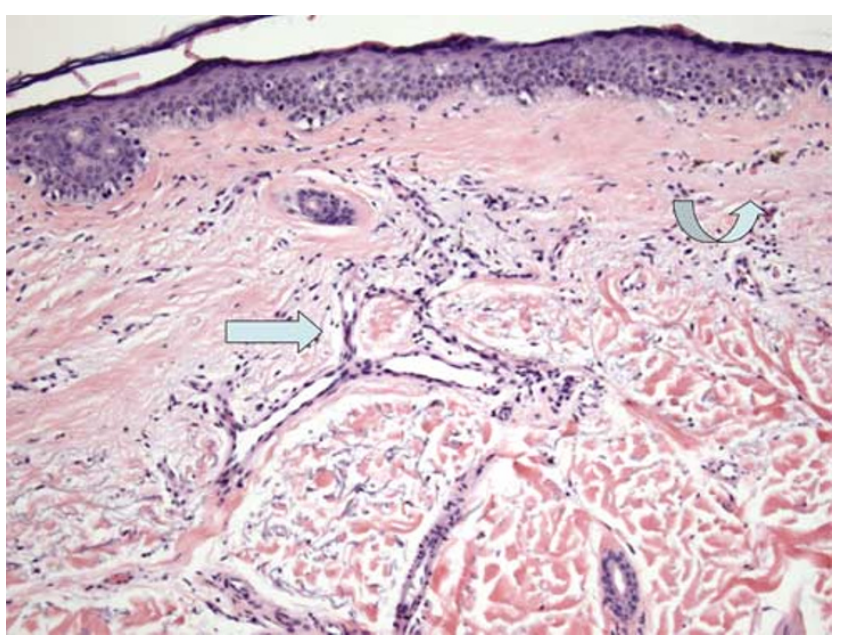

Figure 5 Regression: Regression of over $75 \%$ of the tumor volume of a melanoma is considered a bad prognostic sign. Regression is characterized by haphazard, patternless fibrosis, accompanied by vertically oriented, ectatic blood vessels (straight arrow), melanophages (curved arrow) and patchy lymphocytic infiltration of the stroma. In complete, as opposed to partial regression, there is a total absence of neoplastic melanocytes in the dermis and in the overlying epidermis.

\section{Blood Vessel and Lymphatic Invasion}

The presence or absence of blood vessel and lymphatic invasion should be reported (Figure 7). Some studies have correlated the frequency of angiolymphatic invasion with increasing depth and level of tumor invasion, ${ }^{59}$ while others have shown vascular invasion to be a significant predictor of metastasis ${ }^{90}$ or of reduced survival. ${ }^{11}$ It is perhaps the low frequency of this finding that prevented its emergence as an independent prognostic variable in many earlier series, but more recent data has shown a reduced survivorship of some $40 \%$ over 8 years when angioinvasion is demonstrated in primary tumors in vertical growth phase. ${ }^{10}$ In modern multivariate analytic systems, angioinvasion is equivalent in prognostic import to ulceration, and second only to thickness, as a measure of survival probability. ${ }^{91}$ Angioinvasion is focal within any given tumor, generating potential difficulties with respect to false-negative studies in a single or few paraffin sections. Immunostaining with antibodies such as those against endothelial antigenic targets CD31 and CD34 can prove beneficial in the avoidance of false-positive diagnoses, as stromal retraction artifact around tumor nests can be easily misinterpreted as angioinvasion.

\section{Anatomic Site}

Melanomas of the head and neck area, upper back, axial skeleton, subungual region and/or on the palms or soles have a worse prognosis than do extremity based lesions. ${ }^{2,53}$ 


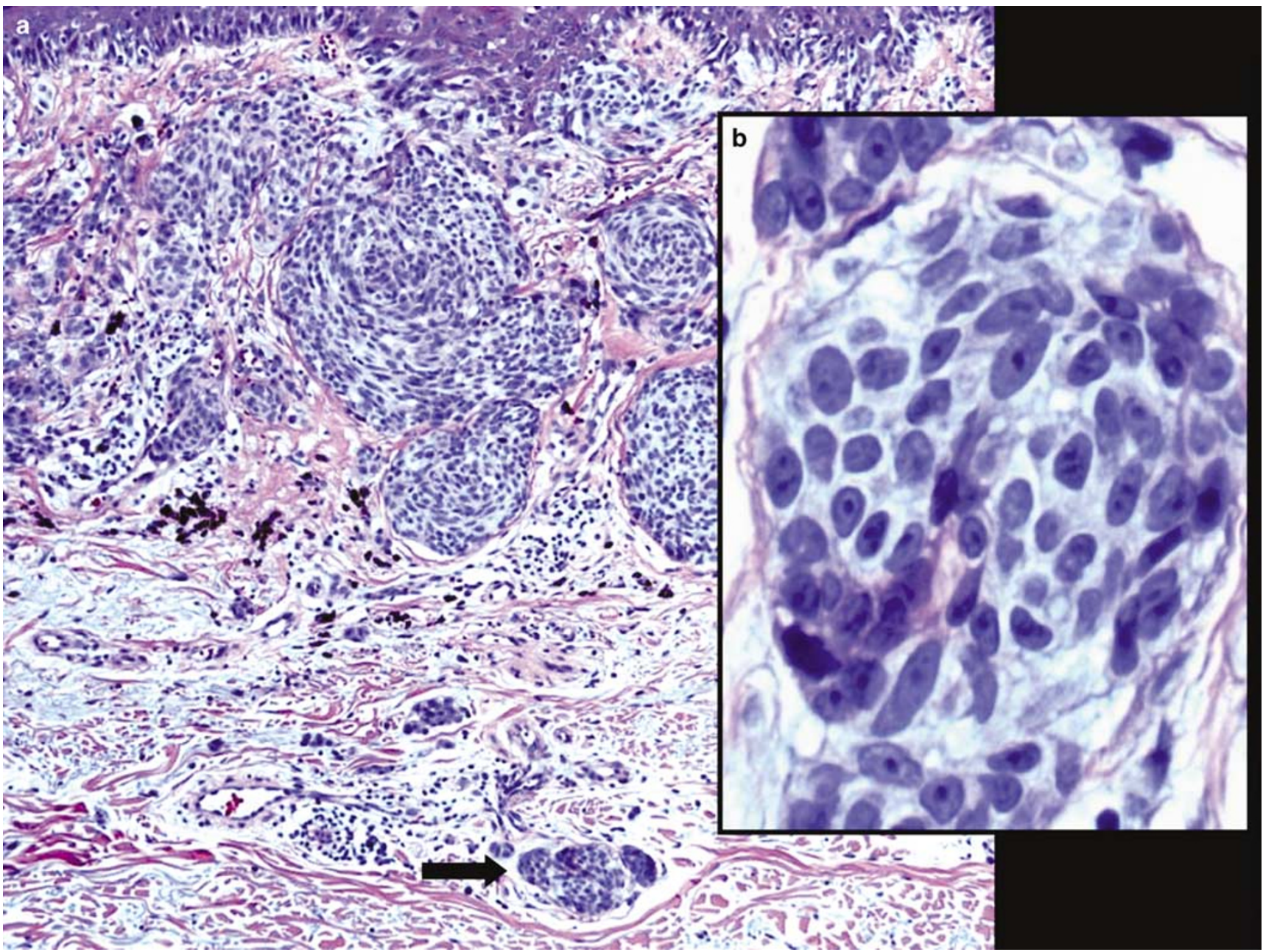

Figure 6 Microscopic satellites: Microscopic satellites, in the most recent AJCC Classification scheme, are considered equivalent to an N1 lymph node metastatic station (a). The satellite is characterized by a group of neoplastic melanocytes greater than $0.05 \mathrm{~mm}$ in diameter, typically located at Clark level III, IV, or V. This neoplastic group is discontinuous (arrow) from the overlying vertical growth phase component demonstrated in the papillary and superficial and reticular dermis. In order to qualify as a microscopic satellite, the melanocytes must have a malignant cytomorphology (b).

\section{Sex}

Women have a better prognosis than men in some but not all studies. ${ }^{10,53}$ The statistical significance of gender is confounded by anatomic site, as women tend to have more extremity-based neoplasms with better survivorship as a result. ${ }^{73}$

\section{Age}

Some studies indicate that patients over the age of 60 years have a worse prognosis. ${ }^{10,53}$

\section{Ulceration}

Ulceration not attributable to trauma in any melanoma, irrespective of the diameter of the ulcer, represents an adverse independent prognostic factor $^{92}$ (Figure 8). The reason that ulceration correlates with substantially increased risk of local recurrence and metastasis likely reflects rapid tumor growth and relative tumor ischemia as a function of rapid growth. By convention we measure the size of any ulcer. $^{93}$ The five year survivorship in Stage I-II melanomas decreased from 80 to $55 \%$ in the presence of ulceration and for Stage III melanomas dropped from 53 to $12 \%$. The majority of melanomas greater than $4.0 \mathrm{~mm}$ in thickness are ulcerated. When tumors had an ulcer diameter of greater than $6.0 \mathrm{~mm}$ the prognosis was even worse. Important changes with respect to the $\mathrm{T}$ classification were therefore effected from 1997 to 2002 (see Table 1). In particular, the T1 level, formerly $0.75 \mathrm{~mm}$, is now set at less than $1.0 \mathrm{~mm}$. T2 tumors are $1.1-2.0 \mathrm{~mm}$ in thickness and T3 tumors $2.1-4.0 \mathrm{~mm}$. A T4 neoplasm is any tumor greater than $4.0 \mathrm{~mm}$ in thickness. The subscript 'a' is added for the absence of ulceration and the subscript ' $b$ ' for the presence of ulceration. Microscopic satellites are considered to 

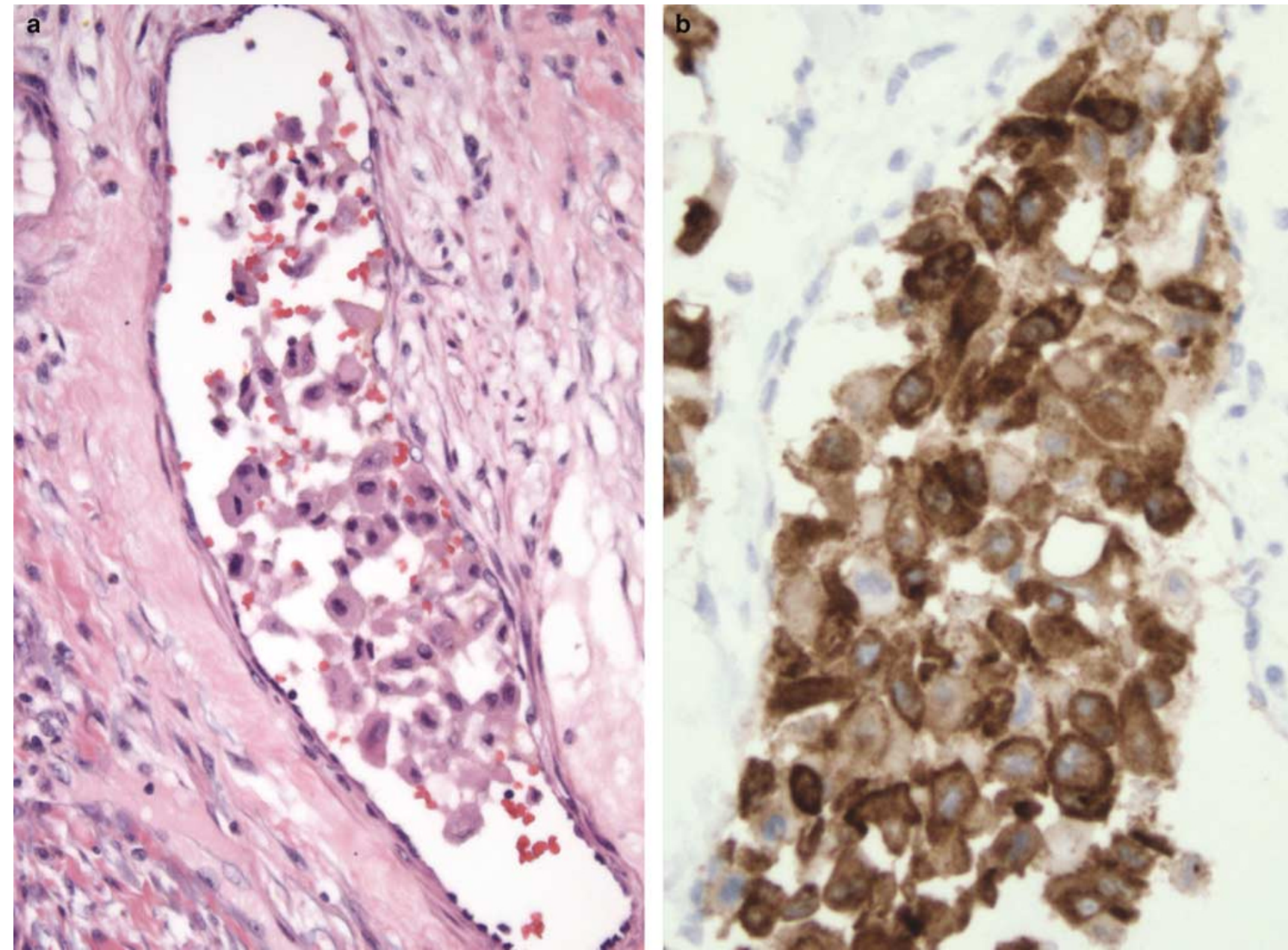

Figure 7 Angioinvasion: Although vascular invasion emerges as a powerful negative prognostic variable only in larger sample sizes, its presence is nonetheless an ominous sign and should be reported. (a) Shows neoplastic epithelioid melanocytes within the lumen of a venule. Their melanocytic character is confirmed by immunohistochemistry with a Melan-A antibody (b).

represent N3 disease in the 2002 staging classification. In the new classification, a T4b tumor (ie greater than $4.0 \mathrm{~mm}$ in thickness with an ulcer present) is associated with roughly $30 \%$ 10-year survivorship. ${ }^{6,94}$

\section{DNA ploidy status}

DNA ploidy status can be assessed in paraffinembedded tissues using static image-analysis software, or in fresh tissue using flow cytometry. Conflicting data are reported, some showing no prognostic import of DNA analysis, ${ }^{95,96}$ but some authors have found a significant association between aneuploidy and diminished survivorship in Stage I and II melanoma patients. ${ }^{97}$ The import of aneuploidy diminishes in multivariate analysis; a majority of melanomas are diploid and thicker tumors tend to be more often aneuploid, diminishing the necessity of ploidy analysis to routine prognostic analysis. The S-phase fraction of a given neoplasm can be similarly expressed; median survival times were 45 months for tumors with an S-phase fraction $>5 \%$ and 19 months for an S-phase fraction $>10 \% .{ }^{98}$ Mitotic rate and S-phase fraction proved to correlate independently with survivorship in one multivariate analysis. ${ }^{99}$

\section{Lymph node status and the sentinel lymph node biopsy}

Survival from melanoma drops progressively from $90 \%$ at 10 years for Stage I to $10 \%$ at 10 years for Stage IV disease. The major independent variable predicting survivorship in thick (ie $>4.0 \mathrm{~mm}$ in depth) melanoma is the presence or absence of micrometastatic disease in the sentinel lymph node. ${ }^{100,101}$ The number of involved lymph nodes has been shown to be a powerful prognosticator with a $P$-value of $0.00001 .^{53}$ Furthermore, microscopic vs macroscopic metastasis is of major significance; if a lymph node is clinically palpable 
a

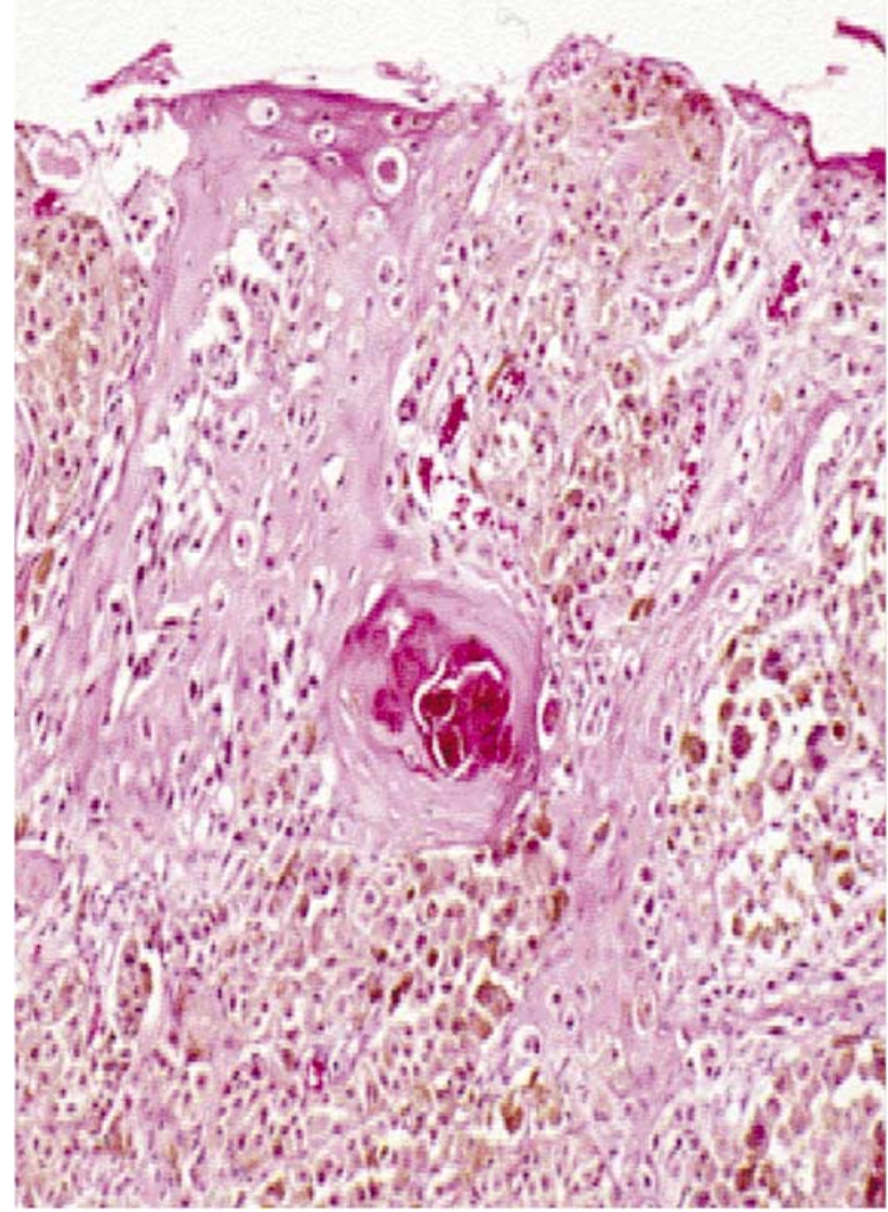

b

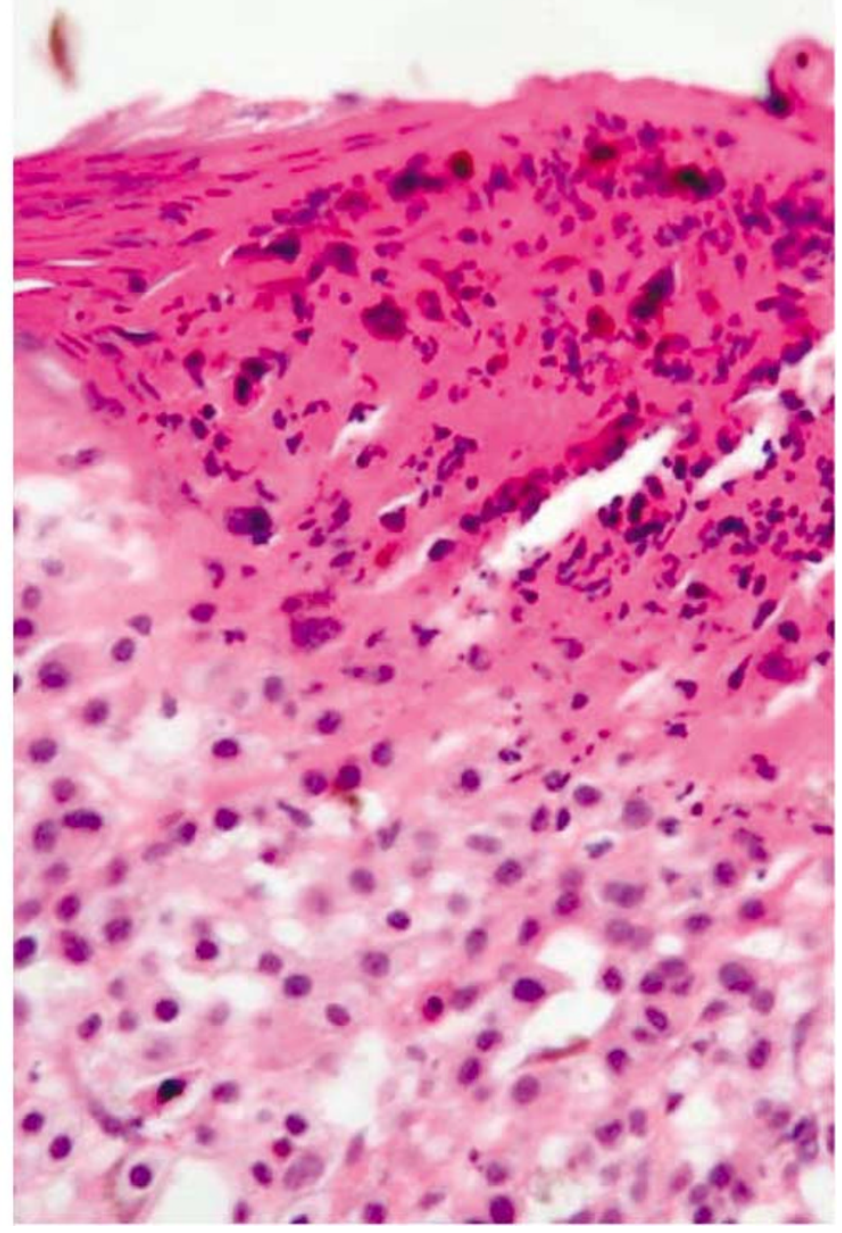

Figure 8 Ulceration: Ulceration emerges as a powerful negative prognostic indicator. It is important not to misinterpret artifactual fragmentation of the epidermal surface (a) from ulceration (b). In the former instance, nests of neoplastic cells can be artifactually extruded to the epidermal surface during processing. The absence of an in vivo response as indicated in b, namely, a fibrinopurulent exudate directly overlying the neoplastic melanocytes and/or papillary dermal stroma, is the clue to a correct interpretation.

in a suspicious fashion and is proven histologically to contain tumor, this has more significance than a clinically negative lymph node containing microscopic disease. With respect to survival by number of positive lymph nodes, the 10-year survivorship drops from $50 \%$ with one positive node to $20 \%$ with $>4$ positive lymph nodes. The number of lymph nodes positive in any definitive resection specimen correlates with the presence of ulceration. With respect to the issue of clinical node positive vs clinical node negative disease, the 10 -year survivorship drops from $50 \%$ in those microscopically positive nodes held clinically to be negative to $30 \%$ in those microscopically positive nodes held clinically to be suspicious for metastatic disease.

\section{Visceral and other remote metastatic sites}

With respect to visceral and other metastatic deposit sites, a high LDH, more than one visceral site involved, male gender and low serum albumin levels all correlate with short survival times ranging from 3 to 7 months.

\section{Satellites}

The presence of microscopic and macroscopic satellites, the former defined by Day et $a l^{86}$ as a nest of tumor cells $0.05 \mathrm{~mm}$ in diameter that is distinct from the main vertical growth phase tumor mass, has been assigned the significance of a micrometastasis and therefore moved to the N-stage classification. ${ }^{5}$ The macroscopic satellite is defined as clinical evidence of tumor deposit(s) $2 \mathrm{~cm}$ from the primary neoplasm along the line of drainage to the nearest regional lymph node station.

\section{Sentinel lymph node biopsy}

The sentinel lymph node biopsy status has proven to be a powerful predictor of survivorship. ${ }^{100,101}$ The 
Table 1 AJCC melanoma TNM classification (revised 2002) ${ }^{7}$ and stage groupings for cutaneous melanomas

\begin{tabular}{lll}
\hline T classification & Thickness $(\mathrm{mm})$ & Ulceration status \\
\hline $\mathrm{T}_{1}$ & $\leq 1.0$ & $\begin{array}{l}\text { a: W/o ulceration and level II or III } \\
\text { b: With ulceration or level IV or V }\end{array}$ \\
$\mathrm{T}_{2}$ & $1.01-2.00$ & $\begin{array}{l}\text { a: W/o ulceration } \\
\text { b: With ulceration }\end{array}$ \\
$\mathrm{T}_{3}$ & $2.01-4.0$ & $\begin{array}{l}\text { a: W/o ulceration } \\
\text { b: With ulceration }\end{array}$ \\
$\mathrm{T}_{4}$ & $>4.0$ & $\begin{array}{l}\text { a: W/o ulceration } \\
\text { b: With ulceration }\end{array}$
\end{tabular}

\begin{tabular}{ll}
\hline N classification & Number of metastatic nodes \\
\hline $\mathrm{N}_{1}$ & One node \\
$\mathrm{N}_{2}$ & Two to three nodes \\
$\mathrm{N}_{3}$ & $\begin{array}{l}\text { Four or more metastatic nodes, or } \\
\text { matted nodes, or in transit met(s)/ } \\
\text { satellite(s) and metastatic node(s) }\end{array}$
\end{tabular}

Nodal metastatic mass

a: Micrometastasis ${ }^{\mathrm{a}}$

b: Macrometastasis ${ }^{\mathrm{b}}$

a: Micrometastasis ${ }^{\mathrm{a}}$

b: Macrometastasis ${ }^{\mathrm{b}}$

c: In transit met(s)/satellite(s) without metastatic nodes

\begin{tabular}{lll}
\hline M classification & Site & Serum LD \\
\hline $\mathrm{M}_{1 \mathrm{a}}$ & Distant skin, SQ or nodal mets & Normal \\
$\mathrm{M}_{1 \mathrm{~b}}$ & Lung metastases & Normal \\
$\mathrm{M}_{1 \mathrm{c}}$ & All other visceral metastases & Normal \\
& Any distant metastasis & Elevated
\end{tabular}

Stage groupings for cutaneous melanomas

\begin{tabular}{|c|c|c|c|c|c|c|c|}
\hline \multicolumn{4}{|c|}{ Clinical staging } & \multicolumn{4}{|c|}{ Pathologic staging } \\
\hline 0 & Tis & No & Mo & 0 & Tis & No & Mo \\
\hline IA & T1a & No & Mo & IA & T1a & No & Mo \\
\hline \multirow[t]{2}{*}{ IB } & $\mathrm{T} 1 \mathrm{~b}$ & No & M0 & IB & $\mathrm{T} 1 \mathrm{~b}$ & No & Mo \\
\hline & T2a & No & Mo & & T2a & No & Mo \\
\hline \multirow[t]{2}{*}{ IIA } & $\mathrm{T} 2 \mathrm{~b}$ & No & Mo & IIA & $\mathrm{T} 2 \mathrm{~b}$ & No & Mo \\
\hline & Т3a & No & Mo & & T3a & No & Mo \\
\hline \multirow{2}{*}{ IIB } & T3b & No & Mo & IIB & T3b & No & Mo \\
\hline & T4a & No & Mo & & T4a & No & Mo \\
\hline IIC & $\mathrm{T} 4 \mathrm{~b}$ & No & Mo & IIC & $\mathrm{T} 4 \mathrm{~b}$ & No & Mo \\
\hline \multirow[t]{11}{*}{ III } & Any T & Any N & M0 & IIIA & $\mathrm{T} 1-4 \mathrm{a}$ & N1a & Mo \\
\hline & & & & & T1-4a & N2a & Mo \\
\hline & & & & IIIB & $\mathrm{T} 1-4 \mathrm{~b}$ & N1a & Mo \\
\hline & & & & & $\mathrm{T} 1-4 \mathrm{~b}$ & $\mathrm{~N} 2 \mathrm{a}$ & Mo \\
\hline & & & & & T1-4a & N1b & Mo \\
\hline & & & & & $\mathrm{T} 1-4 \mathrm{a}$ & $\mathrm{N} 2 \mathrm{~b}$ & Mo \\
\hline & & & & & T1-4a/b & N2c & Mo \\
\hline & & & & IIIC & $\mathrm{T} 1-4 \mathrm{~b}$ & N1b & Mo \\
\hline & & & & & T1-4b & N2b & Mo \\
\hline & & & & & $\mathrm{T} 1-4 \mathrm{~b}$ & N2c & Mo \\
\hline & & & & & Any $\mathrm{T}$ & N3 & Mo \\
\hline IV & Any T & Any N & Any M & IV & Any T & Any N & Any $M$ \\
\hline
\end{tabular}

${ }^{\mathrm{a}}$ Micrometastases are diagnosed after elective or sentinel lymphadenectomy.

${ }^{\mathrm{b}}$ Macrometastases are defined as clinically detectable nodal metastases confirmed by therapeutic lymphadenectomy or when nodal metastasis exhibits gross extracapsular extension.

${ }^{\mathrm{C}}$ Clinical staging includes microstaging of the primary melanoma and clinical/radiologic evaluation for metastases. By convention, it should be used after complete excision of the primary melanoma with clinical assessment for regional and distant metastases.

${ }^{\mathrm{d}}$ Pathologic staging includes microstaging of the primary melanoma and pathologic information concerning regional lymph nodes after partial or complete lymphadenectomy. Patients with pathologic Stage 0 or Stage IA disease are the exception; they do not require pathologic evaluation of their lymph nodes. 
The Sentinel Node

The EORTC Pathologic Staging of Melanoma After Ruiter et al (106)

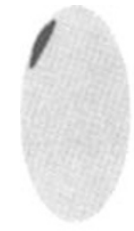

Subcapsular

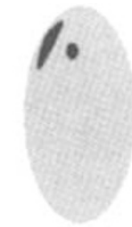

Subcapsular \& parenchymal

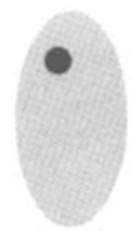

Parenchymal

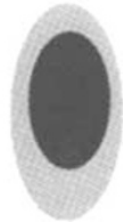

Extensive
Extensive $=>5 \mathrm{~mm}$

Figure 9 The sentinel lymph node: Architectural patterns indicative of probable involvement of nonsentinel lymph nodes. The restriction of clusters of neoplastic melanocytes to a subcapsular location in a sentinel lymph node is associated with a very low (ie less than 5\%) risk of nonsentinel lymph node involvement in the drainage basin. Subcapsular parenchymal deposits or parenchymal deposits of small size in isolation from subcapsular components portend a roughly 10-20\% incidence of nonsentinel lymph node positivity. Extensive lymph node involvement, defined in the quoted study of Ruiter et $a l^{106}$ as a deposit or deposits greater than $5 \mathrm{~mm}$ in diameter, is associated with an incidence of nonsentinel lymph node involvement of roughly $25 \%$.

pattern and volume of lymph node involvement is predictive of the likelihood of finding metastatic deposits in other nodes in the drainage basin at time of completion lymphadenectomy (Figure 9). Although some studies have shown significant improvements in survivorship with elective and/or completion lymphadenectomy, most such series have not. In the data of Cherpelis et $a 1^{102}$, sentinel lymph node status and ulceration were the only independent predictive factors of 5-year survival for tumors $>3 \mathrm{~mm}$ in thickness, while others have shown thickness, ulceration and mitotic rate to all be independent prognostic factors for patients with thick melanomas. ${ }^{103}$ Of the significant modern data, the most compelling is that of Dessureault et al, ${ }^{104}$ who showed a statistically significant reduction of mortality of $68.5 \%$ in those patients with melanomas $>1 \mathrm{~mm}$ in thickness and with positive sentinel lymph node biopsies who went on to completion lymphadenectomy in the setting of clinically nodenegative disease, as opposed to those who waited for clinical evidence of lymph node metastases. For this reason, the sentinel lymphadenectomy must be considered not only an essential weapon in the prognostic armamentarium, but one which leads to potentially beneficial further surgical therapy. We recommend sentinel lymph node biopsy as part of the prognostic work up for a patient with a T2 or T3 tumor, or any patient with a T1 tumor in vertical growth phase or with ulceration or regression at the primary site.

The work of Cochran et a ${ }^{105}$ has provided clues as to which patients with metastases in sentinel lymph nodes will be found to have positive nonsentinel

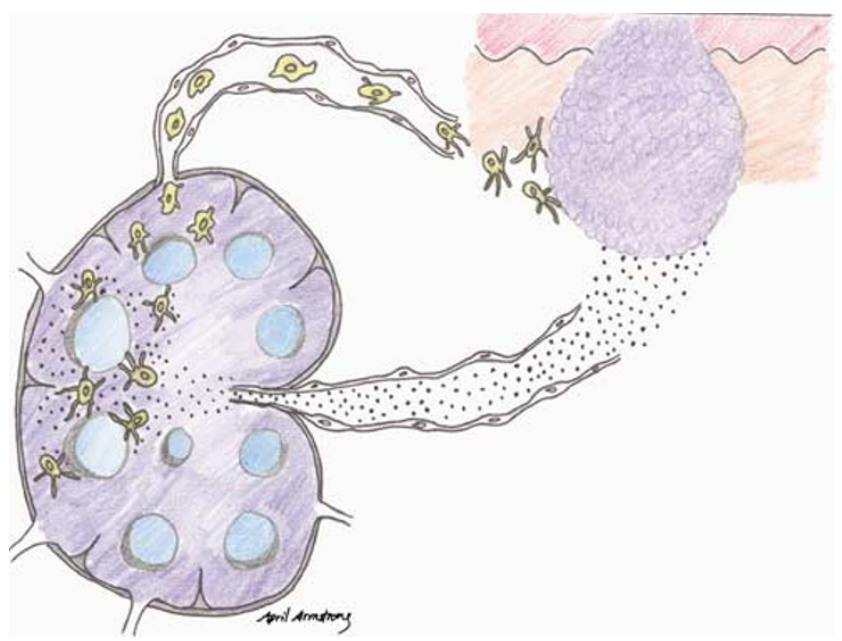

Figure 10 Sentinel lymph node involvement and the 'veiled' antigen-presenting cell. Dendritic antigen-presenting cells migrate from the lymphatic bed of the primary cutaneous melanoma to enter the draining lymph node through afferent lymphatics. While in transit, these dendritic antigen-presenting cells lose their dendritic morphology, the phenotypic hallmark of which is loss of CD-80 and CD-86 expression. If these antigen-presenting cells remain 'veiled' (ie CD-80 and CD-86 negative) when in the paracortex of the lymph node, the possibility of nonsentinel lymph node involvement in the drainage basis may be higher. This process is alleged to reflect immune suppression mediated by some cytokine or cytokines elaborated by the melanoma cells.

lymph nodes at completion lymphadenectomy. In particular, the thickness of the primary melanoma, the relative area of tumor in the sentinel lymph nodes and the density of dendritic leukocytes in the paracortex (Figure 10) all prove to be predictive of the non-sentinel lymph node status. In the hands of the European Organization for Research and Treatment of Cancer (EORTC), the finding of 'extensive' lymph node deposits (namely those $>5 \mathrm{~mm}$ in diameter) correlate with tumor deposits in nonsentinel lymph nodes. ${ }^{106}$

It can be argued that patients with primary cutaneous nevomelanocytic proliferations deemed prognostically indeterminate from a histologic perspective ought to undergo sentinel lymph node biopsy as part of their prognostic microstaging, with the proviso that one would have treated unequivocal melanoma at the same lesional thickness by a sentinel lymph node biopsy and completion lymphadenectomy as indicated. ${ }^{8}$

\section{Conclusion}

The essential elements of the pathology report for primary cutaneous melanoma should include all of the statistically proven prognostic variables as discussed above. Enclosed is the melanoma diagnostic template used at Regional Medical Laboratory in Tulsa, Oklahoma (Table 2). In light of the modern approaches to the assessment of metastatic risk, the old 'quick and dirty report,' namely 'Melanoma, not 
Name:

Case \#:

\section{Location:}

Histological type:

lentigo maligna.

superficial spreading

nodular

acral lentiginous.

not otherwise specified.

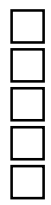

Clark's level:

I.........

II.

III.

IV.

V.

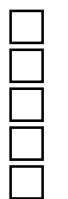

Thickness (Breslow):

$\mathrm{mm}$.

Mitotic index (mitoses $\left./ \mathrm{mm}^{2}\right)$ :

Radial Growth Phase

Vertical Growth Phase

Microscopic satellites

Regression.

Ulceration

diameter

Host immune response

Brisk

Non-brisk

Absent

Neurotropism.

Vascular invasion

Microscopic Satellites.

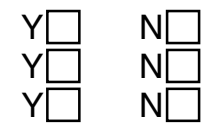

Precursor lesion

Type.....

$\mathrm{Y} \square \quad \mathrm{N} \square$

Margin positive. location if positive

minimum distance from tumor if negative

Lymph nodes involved

number

sentinel lymph node positive

..$Y \square$

$\mathrm{N} \square \quad$ not assessed $\square$

Distant metastases

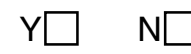
site

This synoptic report is appended to a narrative description of all malignant melanomas except for in situ disease, where the "microstaging" of prognostic risk factors, i.e., ulceration, regression, Breslow depth, etc., is not given. 
otherwise specified: Breslow depth $0.4 \mathrm{~mm}$; margin negative' does the patient a disservice. In the modern era, clinicians and oncologists must recognize specific risk factors for metastatic disease so as to guide adjuvant chemotherapy or immunomodulatory therapy and further surgical therapy including sentinel and completion lymphadenectomy when necessary. The latter has now been shown in large trials to offer significant survivorship benefits. Although the once promising work concerning alpha interferon therapy has not borne fruit, suggesting that no current adjuvant therapy is available to confer increased survival benefits upon patients with metastatic or disseminated disease, evolving adjuvant genetic therapies may soon dramatically impact survivorship. The metastastic potential of any given patient's melanoma needs therefore to be ascertained as precisely and accurately as possible, as in the near future, we anticipate that specific gene-based therapy will target the molecular events of melanomagenesis ${ }^{15}$ and that the subtype of melanoma and its pattern of invasion will illuminate specific molecular therapeutic targets. It is therefore considered essential that patients receiving melanoma diagnoses be provided with the accurate and comprehensive diagnostic assessment upon which these novel therapeutic strategies will be based.

\section{Acknowledgement}

We thank April Armstrong for the illustration in Figure 10.

\section{References}

1 Clark Jr WH. A classification of malignant melanoma in man correlated with histogenesis and biological behaviour. In: Montagna W, Hu F (eds). Advances in the Biology of the Skin, Vol. VIII. Pergamon: New York, 1967, pp 621-647.

2 Clark Jr WH, From L, Bernardino EA, et al. Histogenesis and biologic behavior of primary human malignant melanomas of the skin. Cancer Res 1969;29: 705-726.

3 Breslow A. Thickness, cross-sectional areas and depth of invasion in the prognosis of cutaneous melanoma. Ann Surg 1970;172:902-908.

4 Crowson AN, Barnhill RL, Magro CM, et al. The pathology of melanoma. In: Balch C, Houghton A, Sober A, Soong S-J, Leaman M (eds). Cutaneous Melanoma, 4th edn. Quality Medical Publishers Inc.: St Louis, 2003, pp 171-206.

5 Balch CM, Buzaid AC, Akins MB, et al. A new American Joint Committee on Cancer staging system for cutaneous melanoma. Cancer 2000;88:1484-1491.

6 Balch CM, Soong SJ, Gershenwald JE, et al. Prognostic factors analysis of 17,600 melanoma patients: validation of the American Joint Committee on Cancer melanoma staging system. J Clin Oncol 2001;19: 3622-3634.
7 Balch CM, Gershenwald JE, Buzaid AC, et al. Staging and classification. In: Balch C, Houghton A, Sober A, Soong S-J, Leaman M (eds) Cutaneous Melanoma, 4th edn. Quality Medical Publishers Inc: St Louis, 2003, pp 55-76.

8 Crowson AN, Magro CM, Mihm Jr MC. Malignant melanoma. In: The Melanocytic Proliferations: A Comprehensive Textbook of Pigmented Lesions. John Wiley and Sons: New York, 2001, pp 281-397.

9 Clark Jr EH, Elder DE, Guerry IV D, et al. A study of tumor progression: the precursor lesions of superficial spreading and nodular malignant melanoma. Hum Pathol 1984;15:1147-1165.

10 Clark Jr WH, Elder DE, Guerry D, et al. Model predicting survival in stage I melanoma based on tumor progression. J Natl Cancer Inst 1989;81: 1893-1904.

11 Barnhill RL, Fine JA, Roush GC, et al. Predicting fiveyear outcome for patients with cutaneous melanoma in a population-based study. Cancer 1996;78: 427-432.

12 Day CL, Lew RA, Mihm Jr MC, et al. A multivariate analysis of prognostic factors for melanoma patients with lesions greater than or equal to $3.65 \mathrm{~mm}$ in thickness. The importance of revealing alternate Cox models. Ann Surg 1982;195: 44-49.

13 Day CL, Mihm Jr MC, Sober AJ, et al. Prognostic factors for melanoma patients with lesions 0.76$1.69 \mathrm{~mm}$ in thickness. An appraisal of 'thin' level IV lesions. Ann Surg 1982;195:30-34.

14 Day CL, Mihm Jr MC, Lew RA, et al. Prognostic factors for clinical stage I melanoma of intermediate thickness (1.51-3.39 mm). A conceptual model for tumor growth and metastasis. Ann Surg 1982;195: 35-43.

15 Crowson AN, Magro C, Mihm Jr MC. The biology of melanoma progression: from melanocyte to metastatic seed. In: Hearing VJ, Leong SPL (eds). From Melanocytes to Malignant Melanoma. Human Press: Totowa, NJ, 2006, pp 365-399.

16 Guerry 4th D, Synnestvedt M, Elder DE, et al. Lessons from tumor progression: the invasive radial growth phase of melanoma is common, incapable of metastasis, and indolent. J Invest Dermatol 100;1993: 342S-345S.

17 Taran JM, Heenan PJ. Clinical and histological features of level 2 cutaneous malignant melanoma associated with metastasis. Cancer 2001;91:18221825.

18 Lefevre M, Vergier B, Balme B, et al. Relevence of vertical growth pattern in thin level II cutaeous superficial spreading melanomas. Am J Surg Pathol 2003;27:717-724.

19 Ronan SG, Eng AM, Briele HA, et al. Thin melanomas with regression and metastases. Arch Dermatol 1987;123:1326-1330.

20 Ronan SG, Han MC, Das Gupta TK. Histologic prognostic indicators in cutaneous malignant melanoma. Semin Oncol 1988;15:558-565.

21 Elder DE, Guerry IV D, Epstein MN, et al. Invasive melanomas lacking competence for metastasis. Am J Dermatopathol 1984;6(Suppl 1):55-61.

22 Kesmodel SB, Karakousis GC, Botbyl JD, et al. Mitotic rate as a predictor of sentinel lymph node positivity in patients with thin melanomas. Ann Surg Oncol 2005;12:449-458. 
23 Otto FJ, Goldmann T, Biess B, et al. Prognostic classification of malignant melanomas by combining clinical, histological, and immunohistochemical parameters. Oncology 1999;56:208-214.

24 Conley J, Lattes R, Orr W. Desmoplastic malignant melanoma (a rare variant of spindle cell melanoma). Cancer 1971;28:914-936.

25 Egbert B, Kempson R, Sagebiel. Desmoplastic malignant melanoma. A clinicopathologic study of 25 cases. Cancer 1988;62:2033-2041.

26 Bruijn JA, Mihm Jr MC, Barnhill RL. Desmoplastic melanoma. Histopathology 1992;20:197-205.

27 Fearns C, Dowdle EB. The desmoplastic response: induction of collagen synthesis by melanoma cells in vitro. Int J Cancer 1992;50:621-627.

28 Carlson JA, Dickersin GR, Sober AJ, et al. Desmoplastic neurotropic melanoma. A clinicopathologic analysis of 28 cases. Cancer 1995;75:478-494.

29 Gyorki DE, Busam K, Panageas K, et al. Sentinel lymph node biopsy for patients with cutaneous desmoplastic melanoma. Ann Surg Oncol 2003;10:403-407.

30 Busam KJ, Zhao H, Coit DG, et al. Distinction of desmoplastic melanoma from non-desmoplastic melanoma by gene expression profiling. J Invest Dermatol 2005;124:412-418.

31 HawkinsWG, Busam KJ, Ben-Porat L, et al. Desmoplastic melanoma: a pathologically and clinically distinct form of cutaneous melanoma. Ann Surg Oncol 2005;12:197-199.

32 Iwamoto S, Odland PB, Piepkorn M, et al. Evidence that the p75 neurotrophin receptor mediates perineural spread of desmoplastic melanoma. J Am Acad Dermatol 1996;35(5 Part 1):725-731.

33 Al-Alousi S, Carlson JA, Blessing K, et al. Expression of basic fibroblast growth factor in desmoplastic melanoma. J Cutan Pathol 1996;23:118-125.

34 Clark WH, Mihm MC. Lentigo maligna and lentigo maligna melanoma. Am J Pathol 1969;55:39-54.

35 Reed RJ. Acral lentiginous melanoma. In: New Concepts in Surgical Pathology of the Skin. Wiley: New York, 1976, pp 89-90.

36 Koh HK, Michalik E, Sober AJ, et al. Lentigo maligna melanoma has no better prognosis than other types of melanoma. J Clin Oncol 1984;2:994-1001.

37 Vollmer RT. Malignant melanoma. A multivariate analysis of prognostic factors. Pathol Annu 1989;24: 383-407.

38 Thorn M, Ponten F, Bergstrom R, et al. Clinical and histopathologic predictors of survival in patients with malignant melanoma: a population-based study in Sweden. J Natl Cancer Inst 1994;86:761-769.

39 Weinstock MA, Sober AJ. The risk of progression of lentigo maligna to lentigo maligna melanoma. $\mathrm{Br} \mathrm{J}$ Dermatol 1987;116:303-310.

40 Massi D, Borgognoni L, Franchi A, et al. Thick cutaneous malignant melanoma: a reappraisal of prognostic factors. Melanoma Res 2000;10:153-164.

41 Slingluff Jr CL, Vollmer RT, Reintgen DS, et al. Lethal 'thin' malignant melanoma. Identifying patients at risk. Ann Surg 1988;208:150-161.

42 Kato T, Suetake T, Kumasaka N, et al. Nodular melanoma in 62 Japanese patients: influence of initial surgical treatment of local recurrence and prognosis. J Dermatol 1995;22:723-728.

43 Fidler IJ. Tumor heterogeneity and the biology of cancer invasion and metastasis. Cancer Res 1978;38: 2651-2660.
44 Cox NH, Aitchison TC, Sirel JM, et al. Comparison between lentigo maligna melanoma and other histogenetic types of malignant melanoma of the head and neck. Scottish Melanoma Group. Br J Cancer 1996;73: 940-944.

45 Mehnert JH, Heard JL. Staging of malignant melanoma by depth of invasion. Am J Surg 1965;110: 168-176.

46 Balch CM, Murad TM, Soong SJ, et al. A multlifactorial analysis of melanoma: prognostic histopathological features comparing Clark's and Breslow's staging methods. Ann Surg 1978;188:732-742.

47 Balch CM, Soong SJ, Murad TM, et al. A multifactorial analysis of melanoma. II. Prognostic factors in patients with stage I (localized) melanoma. Surgery 1979;86:343-351.

48 Cascinelli N, Morabito A, Bufalino R. Prognosis of stage I melanoma of the skin. Int J Cancer 1980;26: 733-739.

49 Sondergaard K, Schou G. Survival with primary cutaneous malignant melanoma, evaluated from 2012 cases. A multivariate regression analysis. Virchows Arch A Pathol Anat Histopathol 1985;406: 179-195.

50 Rigel DS, Friedman RJ, Kopf AW, et al. Factors influencing survival in melanoma. Dermatol Clin 1991;9:631-642.

51 Stidham KR, Johnson JL, Seigler HF. Survival superiority of females with melanoma. A multivariate analysis of 6383 patients exploring the significance of gender in prognostic outcome. Arch Surg 1994; 129:316-324.

52 Garbe C, Buttner P, Bertz J, et al. Primary cutaneous melanoma. Identification of prognostic groups and estimation of individual prognosis for 5093 patients. Cancer 1995;75:2484-2491.

53 Balch CM, Soong S, Ross MI, et al. Long-term results of a multi-institutional randomized trial comparing prognostic factors and surgical results for intermediate thickness melanomas (1.0 to $4.0 \mathrm{~mm}$ ). Intergroup Melanoma Surgical Trial. Ann Surg Oncol 2000;7: 87-97.

54 Retsas S, Henry K, Mohammed MQ, et al. Prognostic factors of cutaneous melanoma and a new staging system proposed by the American Joint Committee on Cancer (AJCC): validation in a cohort of 1284 patients. Eur J Cancer 2002;38:511-516.

55 Vollmer RT, Seigler HF. A model for pretest probability of lymph node metastasis from cutaneous melanoma. Am J Clin Pathol 2000;114:875-879.

56 Mihm Jr MC, Googe PB. Problematic Pigmented Lesions. A Case Method Approach. Lea and Febiger: Philadelphia, 1990, pp 241-250.

57 Buttner P, Garbe C, Bertz J, et al. Primary cutaneous melanoma. Optimized cutoff points of tumor thickness and importance of Clark's level for prognostic classification. Cancer 1995;75:2499-2506.

58 Barnhill RB, Katzen J, Spatz A, et al. The importance of mitotic rate as a prognostic factor for localized cutaneous melanoma. J Cutan Pathol 2005;32: 268-273.

59 Schmoeckel C, Braun-Falco O. Prognostic index in malignant melanoma. Arch Dermatol 1978;114: 871-873.

60 Kopf AW, Gross DF, Rogers GS, et al. Prognostic index for malignant melanoma. Cancer 1987;59: 1236-1241. 
61 Scolyer RA, Shaw HM, Thompson JF, et al. Interobserver reproducibility of histopathologic prognostic variables in primary cutaneous melanomas. Am J Surg Pathol 2003;27:1571-1576.

62 Azzola MF, Shaw HM, Thompson JF, et al. Tumor mitotic rate is a more powerful prognostic indicator than ulceration in patients with primary cutaneous melanoma: an analysis of 3661 patients from a single center. Cancer 2003;97:1488-1498.

63 Gimotty PA, Guerry D, Ming MF. Thin primary cutaneous malignant melanoma: a prognostic tree for 10-year metastasis is more accurate than American Joint Committee on Cancer staging. J Clin Oncol 2004;22:3651-3653.

64 Ramsay JA, From L, Iscoe NA, et al. MIB-1 proliferative activity is a significant prognostic factor in primary thick cutaneous melanomas. J Invest Dermatol 1995;105:22-26.

65 Sparrow LE, English DR, Taran JM, et al. Prognostic significance of MIB-1 proliferative activity in thin melanomas and immunohistochemical analysis of MIB-1 proliferative activity in melanocytic tumors. Am J Dermatopathol 1998;20:12-16.

66 Penneys N, Seigfried E, Nahass G, et al. Expression of proliferating cell nuclear antigen in Spitz nevus. J Am Acad Dermatol 1995;32:964-967.

67 Vecchiato A, Rossi CR, Montesco MC, et al. Proliferating cell nuclear antigen (PCNA) and recurrence in patients with cutaneous melanoma. Melanoma Res 1994;4:207-211.

68 Karlsson M, Boeryd B, Carstensen J, et al. Correlation of Ki-67 and PCNA to DNA ploidy, S-phase fraction and survival in uveal melanoma. Eur J Cancer 1996; 32A:357-362.

69 Niezabitowski A, Czajecki K, Rys KJ, et al. Prognostic evaluation of cutaneous malignant melanoma: a clinicopathologic and immunohistochemical study. J Surg Oncol 1999;70:150-160.

70 Goldmann T, Ribbert D, Suter L, et al. Tumor characteristics involved in the metastatic behaviour as an improvement in primary cutaneous melanoma prognostics. J Exp Clin Cancer Res 1998;17:483-489.

71 Reddy VB, Gattuso P, Aranha G, et al. Cell proliferation markers in predicting metastases in malignant melanoma. J Cutan Pathol 1995;22:248-251.

72 Clemente CG, Mihm Jr MC, Bufalino R, et al. Prognostic value of tumor infiltrating lymphocytes in the vertical growth phase of primary cutaneous melanoma. Cancer 1996;77:1303-1310.

73 Piepkorn M, Barnhill RL. Prognostic factors in cutaneous melanoma. In: Barnhill RL, Piepkorn M, Busam KJ (eds). Pathology of Melanocytic Nevi and Malignant Melanoma, 2nd edn. Springer: New York, 2004, pp 372-394.

74 Pastorfide GC, Kibbi AG, de Roa AL, et al. Image analysis of stage I melanoma $(1.00-2.50 \mathrm{~mm})$ : lymphocytic infiltrates related to metastasis and survival. J Cutan Pathol 1992;19:390-397.

75 Mascaro JM, Molgo M, Castel T, et al. Plasma cells within the infiltrate of primary cutaneous malignant melanoma of the skin. A confirmation of its histoprognostic value. Am J Dermatopathol 1987;9: 497-499.

76 Brocker EB, Zwaldo G, Suter L, et al. Infiltration of primary and metastatic melanomas with macrophages of the 25F9-positive phenotype. Cancer Immunol Immunother 1987;25:81-86.
77 Paladagu RR, Yonemeto RH. Biologic behavior of thin malignant melanomas with regressive changes. Arch Surg 1983;118:41-44.

78 Sondergaard K, Hou-Jensen K. Partial regression in thin primary cutaneous malignant melanomas clinical stage I. A study of 486 cases. Virchows Arch A Pathol Anat Histopathol 1985;408:241-247.

79 Naruns PL, Nizze JA, Cochran AJ, et al. Recurrence potential of thin primary melanomas. Cancer 1986;57:545-548.

80 Blessing K, McLaren KM, McLean A, et al. Thin malignant melanomas (less than $1.5 \mathrm{~mm}$ ) with metastasis: a histological study and survival analysis. Histopathology 1990;17:389-395.

81 Shaw HM, McGovern VJ, Milton GW, et al. Malignant melanoma: influence of site of lesion and age of patient in the female superiority in survival. Cancer 1980;46:2731-2735.

82 Kelly JW, Sagebiel RW, Blois MS. Regression in malignant melanoma. A histologic feature without independent prognostic significance. Cancer 1985;56: 2287-2291.

83 Vilmer C, Bailly C, Le Doussal V, et al. Thin melanomas with unusual aggressive behaviour: a report on nine cases. Melanoma Groups of French Federation of Cancer Centers. J Am Acad Dermatol 1996;34:439-444.

84 Byers HR, Bahwan J. Pathologic parameters in the diagnosis and prognosis of primary cutaneous melanoma. Hematol Oncol Clin North Am 1998;12: 717-725.

85 Guitart J, Lowe L, Piepkorn M, et al. Identification of histological features associated with metastasizing thin melanomas: a case-control study of 43 cases. Arch Dermatol 2002;138:603-608.

86 Day CL, Harrist TJ, Gorstein F, et al. Malignant melanoma. Prognostic significance of 'microscopic satellites' in the reticular dermis and subcutaneous fat. Ann Surg 1981;194:108-112.

87 Harrist TJ, Rigel DS, Day Jr CL, et al. 'Microscopic satellites' are more highly associated with regional lymph nodes metastases than is primary melanoma thickness. Cancer 1984;53:2183-2187.

88 Leon P, Daly JM, Synnestvedt M, et al. The prognostic implications of microscopic satellites in patients with clinical stage I melanoma. Arch Surg 1991;126: 1461-1468.

89 Rao UN, Ibrahim J, Flaherty LE, et al. Implications of microscopic satellites of the primary and extracapsular lymph node spread in patients with high-risk melanoma: pathology corollary of Eastern Cooperative Oncology Group Trial E1690. J Clin Oncol 2002; 20:2053-2057.

90 Mraz-Gernhard S, Sagebiel RW, Kashani-Sabet M, et al. Prediction of sentinel lymph node micrometastasis by histological features in primary cutaneous malignant melanoma. Arch Dermatol 1998;134: 983-987.

91 Kashani-Sabet M, Sagabiel RW, Ferreira CM, et al. Vascular involvement in the prognosis of primary cutaneous melanoma. Arch Dermatol 2001;137: 1169-1173.

92 Buzaid AC, Ross MI, Balch CM, et al. Critical analysis of the current American Joint Committee on Cancer staging system for cutaneous melanoma and proposal of a new staging system. J Clin Oncol 1997;15: 1039-1051. 
93 Balch CM, Wilkerson JA, Murad TM, et al. The prognostic significance of ulceration of cutaneous melanoma. Cancer 1980;45:3012-3017.

94 Kim SH, Garcia C, Rodriguez J, et al. Prognosis of thick cutaneous melanoma. J Am Coll Surg 1999;188:241-247.

95 Herzberg AJ, Kerns BJ, Borowitz MJ, et al. DNA ploidy of malignant melanoma determined by image cytometry of fresh frozen and paraffin-embedded tissue. J Cutan Pathol 1991;18:440-448.

96 Skowronek J, Adamska K, Filipiak K, et al. DNA ploidy in malignant melanoma, skin cancer and pigmented nevi. Neoplasma 1997;44:282-288.

97 Kheir SM, Bines SD, Vonroenn JH, et al. Prognostic significance of DNA aneuploidy in stage I cutaneous melanoma. Ann Surg 1988;207:455-461.

98 Karlsson M, Boeryd B, Carstensen J, et al. DNA ploidy and S-phase in primary malignant melanoma as prognostic factors for stage III disease. Br J Cancer 1993;67:134-138.

99 Karjalainen JM, Eskelinen MJ, Nordling S, et al. Mitotic rate and S-phase fraction as a prognostic factor in stage I cutaneous malignant melanoma. Br J Cancer 1998;77:1917-1925.

100 Gershenwald JE, Mansfield PF, Lee JE, et al. Role for lymphatic mapping and sentinel lymph node biopsy in patients with thick ( $>$ or $=4 \mathrm{~mm}$ ) primary melanoma. Ann Surg Oncol 2000;7:160-165.

101 Zettersten E, Sagebiel RW, Miller III JR, et al. Prognostic factors in patients with thick cutaneous melanoma ( $>4 \mathrm{~mm}$ ). Cancer 2002;94:1049-1056.

102 Cherpelis BS, Haddad F, Messina J, et al. Sentinel lymph node micrometastasis and other histologic factors that predict outcome in patients with thicker melanomas. J Am Acad Dermatol 2001;44:762-766.

103 Massi D, Franchi A, Borgognoni L, et al. Thin cutaneous malignant melanoma $(<$ or $=1.5 \mathrm{~mm})$ : identification of risk factors indicative of progression. Cancer 1999;85:1067-1076.

104 Dessureault S, Soong SJ, Ross MI. Improved staging of node-negative patients with intermediate to thick $(>1 \mathrm{~mm})$ with the use of lymphatic mapping and sentinel lymph node biopsy. Ann Surg Oncol 2001; 8:766-770.

105 Cochran AJ, Wen DR, Huang RR, et al. Prediction of metastatic melanoma in nonsentinel nodes and clinical outcome based on the primary melanoma and the sentinel node. Mod Pathol 2004;17: 747-755.

106 Ruiter DJ, Spatz A, van den Oord JJ, et al. Pathologic staging of melanoma. Semin Oncol 2002;29: 370-381. 